\title{
Velocity and Stride Parameters of World-Class 400-Meter Athletes Compared WiTH LESS EXPERIENCED RUNNERS
}

\author{
Christine Hanon $^{1}$ and Bruno GaJer ${ }^{2}$ \\ ${ }^{1}$ Laboratory of Biomechanics and Physiology, French National Institute of Sport, Paris, France; and ${ }^{2}$ French Athletic Federation, \\ Paris, France
}

\begin{abstract}
Hanon, $\mathrm{C}$ and Gajer, B. Velocity and stride parameters of worldclass 400-meter athletes compared with less experienced runners. J Strength Cond Res 23(2): 524-531, 2009-The purpose of this study was to determine, based on the time course of the velocity and stride pattern recorded in each $50-\mathrm{m}$ segment of a 400-m competition, whether elite 400-m runners present the same pacing strategy as less successful athletes. Based on video data, 3 different levels of performance were analyzed: world-class, national, and regional levels for both sexes, with each of the 6 groups comprising 5 subjects. The peak velocity was reached by all athletes between the 50 - and $100-\mathrm{m}$ marks with mean values of 8.96 and $10.12 \mathrm{~m} \cdot \mathrm{s}^{-1}$ for the 5 best women and men, respectively. Peak frequencies were observed in the second and third 50-m segments; peak values were $3.99 \pm 0.13$ for the world-class women (WWC) and 4.12 \pm 0.19 for the men (MWC). A stride length of $2.29 \pm 0.04$ was observed for the WWC and $2.53 \pm 0.08$ for the MWC. The better athletes were able to achieve higher absolute and relative velocities $(97.6 \pm 0.5[\mathrm{MWC}]$ and $96.3 \pm 0.7 \%$ [WWC] of their best performance for $200 \mathrm{~m}$ ) at the 200-m mark compared with the lower-level athletes. Furthermore, the fatigue index was calculated as $22.99,14.43$, and $13.91 \%$ for the world-class, national, and regional levels, respectively. In summary, worldclass runners adopt a more aggressive pacing strategy and demonstrate greater fatigue than the less experienced runners; this might indicate a greater mental commitment and/or a better capacity to run under fatigue.
\end{abstract}

KEY WoRDS pacing strategy, competition, stride length, stride frequency, fatigue index

Address correspondence to Christine Hanon, christine.hanon@insep.fr. 23(2)/524-531

Journal of Strength and Conditioning Research (C) 2009 National Strength and Conditioning Association

\section{INTRODUCTION}

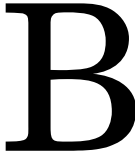
ecause small differences in performance generally determine a competition outcome, information concerning the best way to expend the limited energetic sources available is of considerable interest. However, given the obvious importance of pacing on performance, there are relatively few studies available on this topic. The $400-\mathrm{m}$ run is one of the most demanding athletic events. In this event, which is intermediate between sprint and middle distance, a runner must be able to 1) reach a very high velocity using an economical technique and 2) be capable of preserving the optimal technical characteristics of stride despite intense fatigue. For these reasons, understanding the biomechanical factors in sprint running is critical to performance and is of interest to national coaches to identify areas for improvement to reach world-class levels.

International Athletic Amateur Federation (IAAF) analysis conducted during world championships has focused on timecourse analysis of velocity with a precision of $100 \mathrm{~m}$ and, more recently, $50 \mathrm{~m}$, but the available biomechanical data only allowed comparisons of the start and end of a 400-m run (1) or on the basis of $100 \times 100-\mathrm{m}$ divisions $(2,20)$. Based on the $100 \times 100$-m analysis performed during world-level competition, the peak velocity measured during the $400-\mathrm{m}$ run by Brüggeman and Glad (4) and the IAAF (13) was observed between 100 and $200 \mathrm{~m}$, and peak values of $9.66 \mathrm{~m} \cdot \mathrm{s}^{-1}$ (men) and $8.62 \mathrm{~m} \cdot \mathrm{s}^{-1}$ (women) (Seoul 1988) and $9.63 \mathrm{~m} \cdot \mathrm{s}^{-1}$ (men) and $8.61 \mathrm{~m} \cdot \mathrm{s}^{-1}$ (women) were measured (13). In the last part of the race, a velocity decrease (between the peak velocity and the velocity measured in the last $100 \mathrm{~m}$ ) was systematically observed and determined to be a $13-20 \%$ reduction.

To our knowledge, very few studies have been conducted to date with greater precision (50-m analysis). Sprague and Mann (22) only compared the beginning and the end of the race, demonstrating a peak velocity of $9.51 \mathrm{~m} \cdot \mathrm{s}^{-1}$ and a velocity decrease of $21 \%$. The results collected by the IAAF during the Athens Olympic Games (5) revealed larger differences because the peak velocities were greater $(10.03$ and 8.97 for men and women, respectively) and were reached earlier in the race. Consequently, the calculated decrease in velocity was greater than $20 \%$. The velocity, defined as the

$524 \quad$ Journal of Strength and Conditioning Research

Copyright (c) National Strength and Conditioning Association. Unauthorized reproduction of this article is prohibited. 
Journal of Strength and Conditioning Research" $\mid$ www.nsca-jscr.org

product of the stride length and the stride rate, is therefore the result of an optimal combination of these parameters. The available data show that the peak velocity was obtained with a frequency of $3.74 \mathrm{~Hz}$ and a length of $1.98 \mathrm{~m}$ for women completing the distance in 53.8 seconds (1) and $3.48 \mathrm{~Hz}$ and $2.28 \mathrm{~m}$ for men having covered the distance in 52.8 seconds (20). The velocity decrease was, therefore, the result of both a decrease in stride frequency and length. Nevertheless, the degree of precision obtained by these data does not allow an appreciation of the respective part of both of these parameters and their contributions to the velocity decreases of top-level athletes. Furthermore, to date, accurate data concerning good but less successful runners are not available. This comparative analysis would enable national coaches to determine the differences between their elite athletes to focus either on the first part (maximal velocity limit) or the latter part (fatigue resistance limit) of the race.

Therefore, the aim of the present study was to evaluate the time course of both the velocity and stride parameters (length and frequency) every $50 \mathrm{~m}$ during the $400-\mathrm{m}$ events performed in competition to compare 3 different levels of performance to determine the expertise factors that discriminate world-class runners from their less experienced counterparts.

\section{Methods}

\section{Experimental Approach to the Problem}

To examine the effect of expertise on the pacing strategy of 400-m runners, the evolution of velocity and biomechanical parameters were studied. This comparison used data from 50 -m segments of competition events from the start to the end of each race.

\section{Subjects}

Three different levels of performance were analyzed: worldclass, national, and regional levels for both sexes. Each of the 6 groups had 5 subjects. The mean running time for each group was significantly different from every other group (Table 1 ). The training status of the subjects was $5-7$ sessions a week for national standard and 3-5 times a week for regional level.

\section{Procedures}

The study was performed using 2 different video methodologies: one for the world-class level and the other for the national and regional levels.

TABLE 1. Average $+S D$ of the performances.

\begin{tabular}{lccc}
\hline & World-class level & National level & Regional level \\
\hline Men & $44.43 \pm 0.16$ & $46.83 \pm 0.52$ & $48.24 \pm 0.31$ \\
Women & $49.97 \pm 0.33$ & $53.06 \pm 0.50$ & $55.33 \pm 0.30$ \\
\hline
\end{tabular}

Each group $(n=5)$ is homogeneous, and the 6 groups were statistically different, $p<0.05$.

\section{World-Class-Level Analysis}

The analysis was performed using the IAAF pictures recorded during world championships. Nine video cameras operating at $50 \mathrm{~Hz}$ were placed perpendicular to the running direction for filming the runners when passing through markers that were placed every $50 \mathrm{~m}$. Sequences were digitized to register the very moment at which each athlete passed the markers that had been filmed before. Mean stride number per segment was determined by visually counting the number of strides for each 50-m segment from the video document. If the final stride landed short or long of the $50-\mathrm{m}$ line, a percentage of the stride was determined for that segment. This was done by taking into account the time at $\mathrm{n}$ (foot contact before the line) and the time at $\mathrm{n}+1$ (foot contact after the line) and then calculating a percentage. Example of calculation:

$$
\begin{aligned}
50 \mathrm{~m}= & 24 \text { full strides, the } 25 \text { th } \\
& \text { being on both sides of the line. }
\end{aligned}
$$

Time at 24th contact: 30.75 seconds; time at 25 th contact: 30.97 ; thus, the stride duration is 0.22 seconds.

Time at the line: 30.92 seconds (IAAF data).

Between the 24th step and the line: 0.17 seconds (30.92$30.75)$; that, is $77 \%[(0.22 / 0.17) \times 100]$ of the stride duration. The following $23 \%$ was then considered in the next $50-\mathrm{m}$ portion.

The total step numbers were then 24.77 , and that value was used to calculate the mean stride length for that segment.

Mean stride frequency was calculated from the stride length and the velocities as follows: stride frequency $=$ velocity $/$ stride length.

\section{National or Regional Analysis}

The competition was an official meeting located at sea level in the northern hemisphere during the competitive season (end of June). This was a selective international event. The athletes signed an informed consent document before the investigation and answered questions regarding their best performance and morphologic data. The investigation was approved by an institutional review board for the use of human subjects.

The temperature was $22^{\circ}$, and the wind was inferior to $1.5 \mathrm{~m} \cdot \mathrm{s}^{-1}$. Before the competition, the track was marked every $50 \mathrm{~m}$. On both sides of this line, additional marks were placed every $20 \mathrm{~cm}$ on $140 \mathrm{~cm}$. The video system used consisted of 16 videotape recorders (Panasonic Super-VHS) with a double framework that allows one to obtain 50 frames per second and, thus, to decrease the error of measurement to 0.01 seconds for every $50 \mathrm{~m}$. Three panoramic videotape recorders were placed in the stands (approximately $25 \mathrm{~m}$ from the track) to facilitate the determination of stride numbers for each $50-\mathrm{m}$ segment. 
These cameras observed corridors 1-3, 4-8, and 1-8 (help camera), respectively. The remaining 13 cameras were synchronized and were used to obtain the time for each 50 -m segment. When no gap existed between the corridors (such as in the last $150 \mathrm{~m}$ ), only 1 camera was necessary. However, when an important gap existed (such as in the first $250 \mathrm{~m}), 2$ or 3 cameras were used.

The average stride length (distance / stride numbers) was then calculated on each 50-m part (margin of error: $2 \times 5 \mathrm{~cm}$ ). The exact stride lengths were calculated with the help of the additional marks on both sides of the lines.

\section{Statistical Analyses}

The effect of distance and the effect of expertise on velocity, stride rate, and stride length were determined by repeatedmeasures analysis of variance. The significance level was set at $p \leq 0.05$.

\section{Results}

\section{The Velocity}

The velocity was an average velocity for the considered $50-\mathrm{m}$ part, calculated from times recorded for every $50 \mathrm{~m}$.
As observed in Figure 1, the peak velocity was reached for all athletes between the 50 - and $100-\mathrm{m}$ marks. The velocities of the world-class group were significantly greater than the other levels during the first segment and remained greater until the 150 - to $200-\mathrm{m}$ segment in the women and until the 350 - to $400-\mathrm{m}$ segment in the men.

Three distinct periods in velocity were observed:

-An acceleration phase from the start until the end of the first bend (around $100 \mathrm{~m}$ and approximately 11-13 seconds)

-A progressive decrease of the velocity until $300 \mathrm{~m}$

-A great decrease in velocity during the last $100 \mathrm{~m}$

This final decrease in velocity was greatest for the worldclass level, particularly in the women's group. Furthermore, the fatigue index (peak velocity - final velocity / peak velocity) $\times 100$ was $22.99,14.43$, and $13.91 \%$ for the worldclass, national, and regional levels, respectively.

\section{Stride Length}

As seen in Figure 2a, the peak values of stride length were $2.29 \pm 0.04,2.21 \pm 0.07$, and $2.16 \pm 0.05 \mathrm{~m}$, respectively, for women's world (WWC), national (WN), and regional (WR) runners and $2.53 \pm 0.08,2.40 \pm$ 0.06 , and $2.35 \pm 0.08 \mathrm{~m}$ for men's world (MWC), national $(\mathrm{MN})$, and regional (MR) runners, respectively (Figure $2 \mathrm{~b}$ ). This peak was observed at 100 $150 \mathrm{~m}$ after the onset of the 400-m running except for the national-level runners, who reached their peak value one segment earlier. The stride length values of the world-class runners were significantly greater than those of the other runners, except for in the last segment (Figure 2, Table 2).

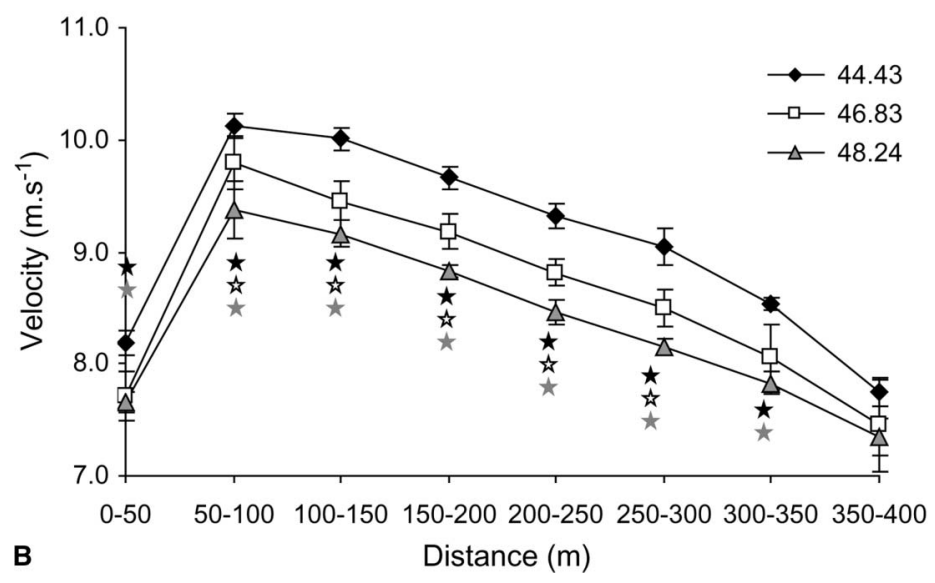

Figure 1. Time course of velocity for women (a) and men (b). For each group, $n=5$. Black stars, gray stars, and white stars indicate that the difference is significant $(p<0.05)$ between world-class and national level, between world-class and regional level, and between national and regional level, respectively.

\section{Step Frequency}

Maximum step frequency was reached between 50 and $100 \mathrm{~m}$ when the velocity was maximal; peak step frequency was $3.99 \pm$ $0.13,3.89 \pm 0.14$, and $3.86 \pm$ $0.16 \mathrm{~Hz}$ for the WWC, WN, and WR runners (Figure 3a). The final decrease in step rate was particularly important from 250 to $400 \mathrm{~m}$ in the WWC group and contrary to the $\mathrm{WN}$ and WR. Except for the last two 50$\mathrm{m}$ runs, the differences were not significant between the groups of women runners. In the men's 


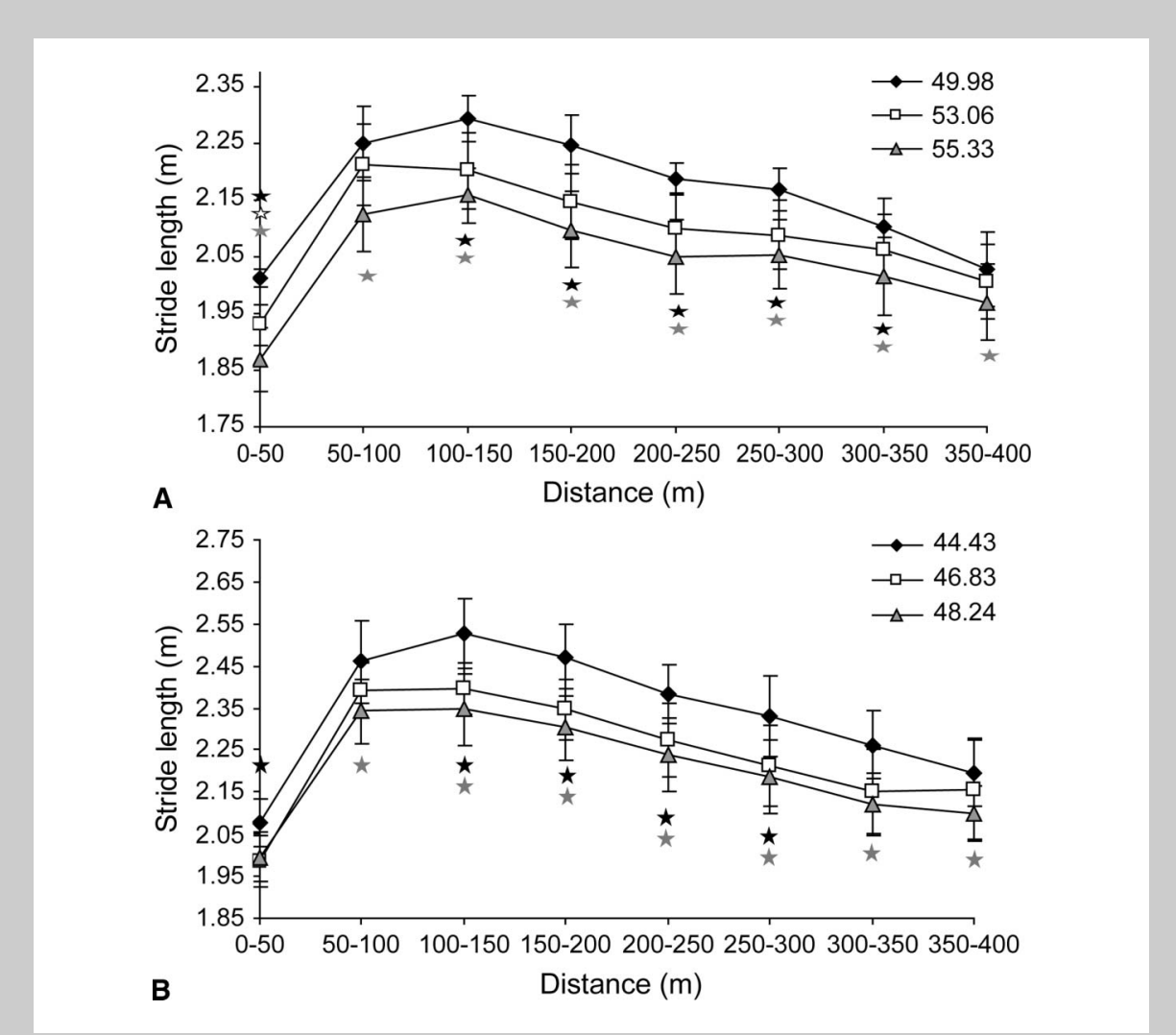

Figure 2. Time course of stride length for women (a) and men (b). For each group, $n=5$. Black stars, gray stars, and white stars indicate that the difference is significant $(p<0.05)$ between world-class and national level, between world-class and regional level, and between national and regional level, respectively.
As observed in Table 3, the respective contributions of stride length and frequency in the velocity decrease are attributable to stride length $(200-300 \mathrm{~m})$, then to both stride length and velocity $(300-350 \mathrm{~m})$, and, finally, to stride frequency (350-400 m).

The velocity decrease is expressed as a percentage of the velocity in the previous interval. The stride length and frequency results are expressed as percentages of each parameter in the velocity decrease (Table 4 ).

\section{Discussion}

The results reported in this study confirm that when data are recorded $50 \times 50 \mathrm{~m}$, the maximal and minimal values in velocity, stride length, and frequency are greater than when recorded with a precision of $100 \mathrm{~m}$. The top world-level athlete is characterized by a more aggressive pacing strategy than runners at the other levels of performance $(96 \%$ of the personal best at the $200-\mathrm{m}$ mark) and by a greater stride groups (Figure 3b), the peak values for MWC, MN, MR, were $4.12 \pm 0.19,4.10 \pm 0.16$, and $4.00 \pm 0.16 \mathrm{~Hz}$, respectively. The differences between frequency values were never significantly different between groups. The decrease in the last $100 \mathrm{~m}$ was similar for the 3 levels of men runners.

TABLe 2. Size and maximal stride length of the groups.

\begin{tabular}{|c|c|c|c|c|}
\hline & \multicolumn{2}{|c|}{ Women } & \multicolumn{2}{|c|}{ Men } \\
\hline & Size $(m)$ & $\mathrm{MSL}(\mathrm{m})$ & Size $(m)$ & MSL (m) \\
\hline WCL & $-1.70 \pm 0.04$ & 2.29 & $1.84 \pm 0.06$ & 2.53 \\
\hline NL & $1.70 \pm 0.05$ & 2.21 & $1.85 \pm 0.05$ & 2.40 \\
\hline $\mathrm{RL}$ & $1.67 \pm 0.05$ & 2.16 & $1.81 \pm 0.05$ & 2.35 \\
\hline
\end{tabular}

$\mathrm{MSL}=$ maximal stride length recorded during the 400-m run; $\mathrm{WCL}=$ world-class level; $\mathrm{NL}=$ national level; $\mathrm{RL}=$ regional level.

For each group, $n=5$. length. The velocity decrease in the last part of the 400-m run was more dramatic in the world-class runners. This velocity decrease is attributable primarily to stride length (at 200-300 $\mathrm{m})$, then (at 300-350 m) to both stride length and frequency, and, finally, to stride frequency in the last $50 \mathrm{~m}$.

The peak velocities $\left(10.12 \mathrm{~m} \cdot \mathrm{s}^{-1}\right.$ for MWC and $8.96 \mathrm{~m} \cdot \mathrm{s}^{-1}$ for WWC) are about $10 \%$ greater than the velocities obtained when a race is analyzed $100 \times 100 \mathrm{~m}(2,4)$ for the same level of performance. The peaks of velocity of the world-class, national, and regional groups are significantly different from each other $(p<0.05)$ and can be attributed to the maximal velocity of each runner and/or the pacing strategy adopted. Based on the information in Table 5, it is possible to observe that, on one hand, the world-class runners had a better $200-\mathrm{m}$ best performance but that, on the other hand, they used a greater percentage of their maximal velocity (96-97\% of best performance). Other investigations have shown that an all-out or a quasi-all-out strategy allows for the best results on a 60 -s cycling exercise $(6,7)$ and on a 2 -minute kayak exercise (3). This could indicate greater risk-taking, supported by obvious physiological capacities allowing this risk taking. The increase in velocity was obtained by an increase in both step length and frequency as previously described by $100-\mathrm{m}$ 


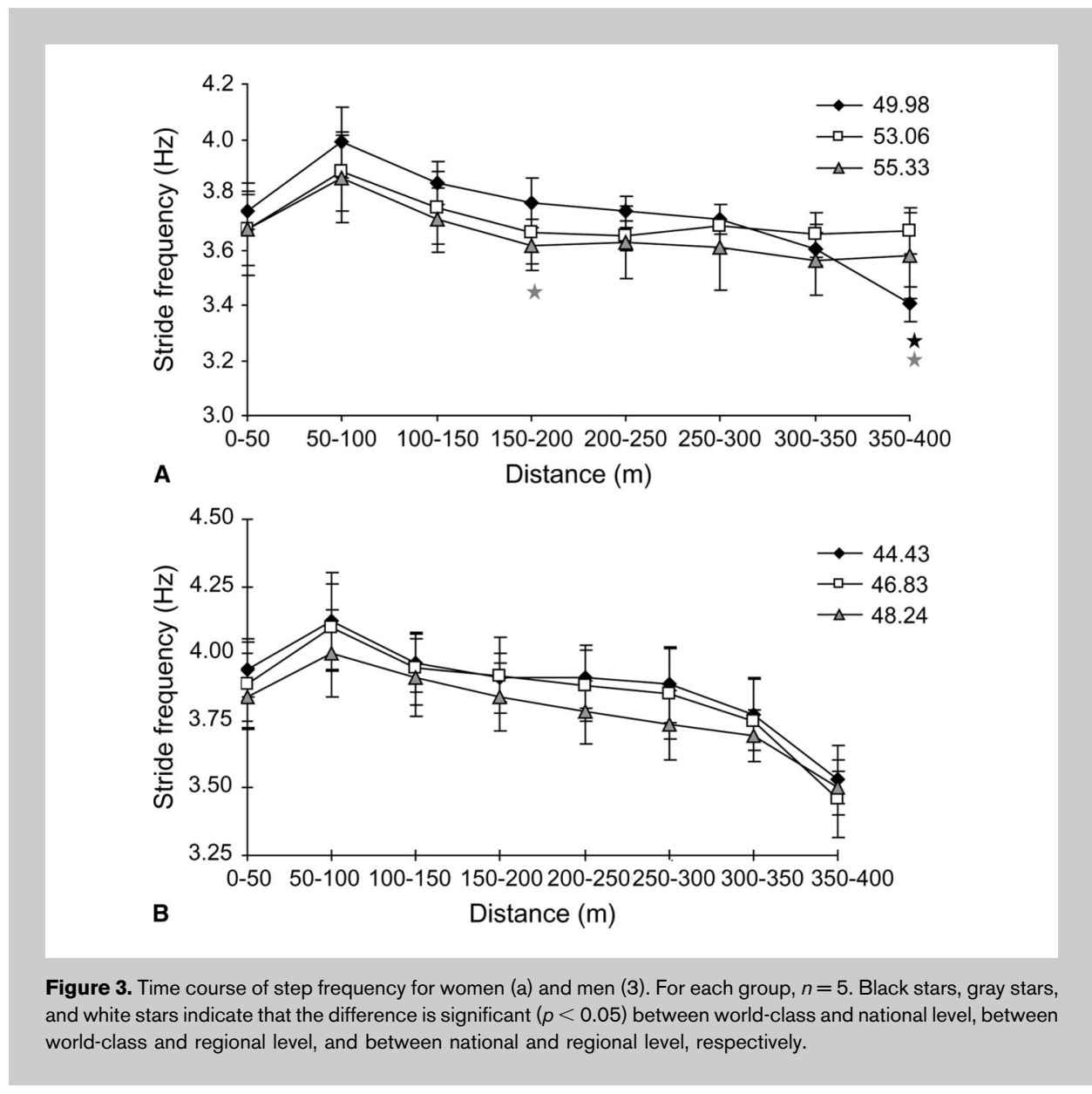

to be lower compared with those recorded for the $200 \mathrm{~m}$ (4.50 for men and 4.48 for women) and for the $100 \mathrm{~m}$ (4.77 for men and 4.62 for women) (5). However, during the $400 \mathrm{~m}$, the peak stride length values (2.53 and 2.29 $\mathrm{m})$ were greater than the peak values recorded for the $100 \mathrm{~m}$ $(2.43$ and $2.23 \mathrm{~m})$, but they were nearer to those revealed for the $200 \mathrm{~m}$ (2.57 and $2.39 \mathrm{~m})$, particularly in men athletes. Mero and Peltola (18) conclude that relaxation times can be used to evaluate the economy of running locomotion. The particular challenge of this distance is that it has to be run very near to maximal velocity for a duration of 45 or 50 seconds. One can hypothesize that the best runners are capable of an optimal and, therefore, economical combination of length and frequency. We can hypothesize that the difficulty is in achieving a greater stride length while at the same time keeping a reserve in regard to maximal stride length, aim-

analysis (9). During the $400 \mathrm{~m}$, the maximal step frequency was reached during the second part of the first turn when the peak velocity was obtained. The peak stride length was achieved later, at the beginning of the first straight. One can hypothesize that these differences, when compared with the $100 \mathrm{~m}$, are attributable to the presence of the curves in the track.

Stride frequencies recorded for the world-class athletes at $400 \mathrm{~m}(4.12 \mathrm{~Hz}$ for the men and $3.99 \mathrm{~Hz}$ for the women) seem ing to run economically and, therefore, as relaxed as possible. This capacity to exactly regulate pace is supposed to ensure the maintenance of a motor-unit reserve (23).

All the distances from $800 \mathrm{~m}$ to marathon are characterized by a stride frequency of around $3.50 \mathrm{~Hz}(21,10)$. A stride frequency greater than $4 \mathrm{~Hz}$ only has been recorded in the 100,200 , and $400 \mathrm{~m}$ and seems to be a problem when the exercise duration is greater than 1 minute. In the same way,

TABLE 3A. Velocity decrease from 200 to $300 \mathrm{~m}$.

\begin{tabular}{|c|c|c|c|c|c|c|}
\hline & \multicolumn{3}{|c|}{ Women } & \multicolumn{3}{|c|}{ Men } \\
\hline & WCL (\%) & $\mathrm{NL}(\%)$ & $\mathrm{RL}(\%)$ & WCL (\%) & $\mathrm{NL}(\%)$ & $\mathrm{RL}(\%)$ \\
\hline Velocity & -4.96 & -1.91 & -2.5 & -6.3 & -7.4 & -7.7 \\
\hline Stride length & -3.55 & -2.79 & -2.38 & -5.7 & -6 & -4.8 \\
\hline Stride frequency & -1.59 & +0.54 & -0.27 & -0.8 & -1.78 & -2.9 \\
\hline
\end{tabular}

$\mathrm{WCL}=$ world-class level; $\mathrm{NL}=$ national level, $\mathrm{RL}=$ regional level.

For each group, $n=5$. 
TABLE 3в. Velocity decrease from 300 to $350 \mathrm{~m}$.

\begin{tabular}{lccccccc}
\hline & \multicolumn{3}{c}{ Women } & & \multicolumn{3}{c}{ Men } \\
\cline { 2 - 3 } & WCL (\%) & NL (\%) & RL (\%) & & WCL (\%) & NL (\%) & RL (\%) \\
\hline Vitesse & -5.84 & -2.2 & -2.97 & & -5.75 & -5.2 & -3.9 \\
Stride length & -3.22 & -1.43 & -1.46 & & -3 & -2.7 & -3.2 \\
Stride frequency & -2.96 & -0.81 & -1.38 & & -2.8 & -2.6 & -1.1 \\
\hline
\end{tabular}

$\mathrm{WCL}=$ world-class level; $\mathrm{NL}=$ national level, $\mathrm{RL}=$ regional level.

Table 3c. Velocity decrease from 350 to $400 \mathrm{~m}$.

\begin{tabular}{|c|c|c|c|c|c|c|}
\hline & \multicolumn{3}{|c|}{ Women } & \multicolumn{3}{|c|}{ Men } \\
\hline & WCL (\%) & $\mathrm{NL}(\%)$ & $\mathrm{RL}(\%)$ & WCL (\%) & $\mathrm{NL}(\%)$ & $\mathrm{RL}(\%)$ \\
\hline Vitesse & -8.97 & -2.39 & -1.81 & -9.1 & -7.6 & -6.1 \\
\hline Stride length & -3.33 & -2.43 & -2.47 & -2.6 & +0.4 & -0.9 \\
\hline Stride frequency & -5.55 & +0.55 & +0.56 & -6.4 & -7.8 & -5.1 \\
\hline
\end{tabular}

$\mathrm{WCL}=$ world-class level; $\mathrm{NL}=$ national level, $\mathrm{RL}=$ regional level.

TABle 4. Comparative study between best performance in the $200-\mathrm{m}$ run and the time at $200 \mathrm{~m}$ during the $400-\mathrm{m}$ run.

\begin{tabular}{|c|c|c|c|c|c|c|c|c|}
\hline & \multicolumn{4}{|c|}{ Men } & \multicolumn{4}{|c|}{ Women } \\
\hline & 200R (s) & $200 \mathrm{~T}(\mathrm{~s})$ & Dif (s) & $\%$ & $200 R(s)$ & $200 \mathrm{~T}(\mathrm{~s})$ & Dif (s) & $\%$ \\
\hline WCL & $20.72 \pm 0.05$ & $21.22 \pm 0.08$ & $0.51 \pm 0.11$ & $97.62 \pm 0.51$ & $22.98 \pm 0.29$ & $23.80 \pm 0.18$ & $0.87 \pm 0.18$ & $96.34 \pm 0.75$ \\
\hline $\mathrm{NL}$ & $21.09 \pm 0.24$ & $22.33 \pm 0.42$ & $1.24 \pm 0.29$ & $94.44 \pm 1.21$ & $24.29 \pm 0.65$ & $25.31 \pm 0.17$ & $1.09 \pm 0.68$ & $95.72 \pm 2.66$ \\
\hline $\mathrm{RL}$ & $21.59 \pm 0.32$ & $23.00 \pm 0.25$ & $1.41 \pm 0.52$ & $93.89 \pm 2.18$ & $24.63 \pm 0.27$ & $26.26 \pm 0.25$ & $1.64 \pm 0.19$ & $93.77 \pm 0.73$ \\
\hline
\end{tabular}

For each group, $n=5$. WCL $=$ world-class level; $\mathrm{NL}=$ national level, $\mathrm{RL}=$ regional level.

$200 \mathrm{R}=$ average $200-\mathrm{m}$ best performances of the runners; $200 \mathrm{~T}=$ time at $200 \mathrm{~m}$ during the $400-\mathrm{m}$ run; $\%=200 \mathrm{~T}$ expressed as a percentage of 200R; Dif $=$ difference between $200 \mathrm{~T}$ and $200 \mathrm{R}$ in seconds.

TABLE 5. Stride lengths and stride frequencies for different distances.

\begin{tabular}{lccccccc}
\hline & $100 \mathrm{~m}$ & $200 \mathrm{~m}$ & $400 \mathrm{~m}$ & $800 \mathrm{~m}$ & $1500 \mathrm{~m}$ & $5000 \mathrm{~m}$ & $10,000 \mathrm{~m}$ \\
\hline Length $(\mathrm{m})$ & 2.43 & 2.57 & 2.53 & 2.1 & 2 & 1.8 & 1.75 \\
Frequency $(\mathrm{Hz})$ & 4.77 & 4.5 & 4.12 & 3.67 & 3.53 & 3.5 & 3.46 \\
ratio & 1.96 & 1.75 & 1.63 & 1.75 & 1.77 & 1.94 & 1.98 \\
\hline
\end{tabular}

Data are from Scholich (21), Brüggeman and Glad (4), and the present data (for men only). 
an important difference in stride length exists between distances less than and greater than $400 \mathrm{~m}$. From this biomechanical point of view, $400 \mathrm{~m}$ is more similar to the $200-\mathrm{m}$ than to the $800-\mathrm{m}$ distance. When comparing the ratios between stride length and stride frequency among distances from 100 to $10000 \mathrm{~m}$ (Table 5), the $400 \mathrm{~m}$ seems to be unique in that during this distance, stride length is more elevated compared with stride frequency.

Although the difference in velocity between the 3 levels of performance considered in the present study is attributable both to stride frequency and stride length, the only significant difference between levels concerns stride length. As seen in Table 2, although the subjects sizes are not different, their peak stride lengths are $8 \mathrm{~cm}(\mathrm{~W})$ and $13 \mathrm{~cm}(\mathrm{M})$ greater for the world-class athletes than for the national athletes. The difference between the best and the less experienced runners is particularly important in the second straight and at the beginning of the second bend (100-250 m). If we compare world-class and national levels at $150 \mathrm{~m}$ after the onset of the race, it is possible to observe that the respective velocities (10 and $9.45 \mathrm{~m} \cdot \mathrm{s}^{-1}$ for the world and national levels, respectively) are only the results of differences in stride length $(2.53$ and $2.40 \mathrm{~m})$ because the stride frequencies are similar $(3.96$ and $3.95 \mathrm{~Hz}$ ). Is this result the consequence of a strategic choice, or is it an effect of muscular capacities? Previously, stride length has been shown to be correlated with the peak force occurring during the propulsion phase (16). It is therefore possible to hypothesize that one of the major differences between the best athletes and less successful athletes concerns force production during contact times.

The decrease in velocity is greater (more than $20 \%$ between the peak and the final velocities) than previously described from $100 \times 100$-m studies $(14$ to $9 \%)(2,4)$. Moreover, it is interesting to note that the decrease in velocity recorded in the last $50 \mathrm{~m}$ and in the last $100 \mathrm{~m}$ was more important for the world-class athletes than for the other levels of athletes (Tables 3 and 4), confirming that the $18 \%$ velocity decrease previously recorded with less successful athletes (20) could indicate a greater mental commitment or a better capacity to run under fatigue. This fatigue level has been shown to be particularly important in this distance as revealed by lactate concentrations greater than $20 \mathrm{mmol} \cdot \mathrm{L}^{-1}(15)$, depleted values of phosphocreatine $(\mathrm{PCr})$, and significant decreases of adenosine triphosphate (ATP) (12). Kinderman and Schnabel (14) have shown that the $400-\mathrm{m}$ runners are able to reach very low $\mathrm{pH}$ (until 6.88) compared with middle-distance runners. These very low values are confirmed in elite 400 -m runners (11). In the last $50 \mathrm{~m}$, when the $\mathrm{pH}$ is supposed to be very low, both stride frequency and length decreased. The decrease in stride frequency did not differ according to level of performance. Nevertheless, in the last $50 \mathrm{~m}$, the decrease in frequency was more important than the decrease in length. This decrease in stride frequency observed under fatigue has been shown to be related to the decrease in vertical leg stiffness (19). It should be noted that the difference between the peak and the final stride length was significantly greater for the world-class group than for the other groups (Figure $2 \mathrm{a}$ and $2 \mathrm{~b}$ ).

In a previous study, Nummela et al. (20) found that dropjump performance was impaired by $39 \%$ after a maximal 400 $\mathrm{m}$ sprint; this decrease was correlated with the increase in blood lactate concentration. The electromyographic activity in the active muscles increased significantly during the $400 \mathrm{~m}$, and the authors conclude that additional motor units were activated to compensate for the apparent failure of muscle contractility as a consequence of the metabolic acidosis. The progressive reduction in running speed must result from a combination of changes occurring in the muscle and a complex regulation by the central nervous system, which is based on afferent feedbacks protecting against harmful disturbances to homeostasis (23).

During the entire $400-\mathrm{m}$ run, stride length rather than frequency seems to be the discriminating biomechanical parameter between levels of performance.

As suggested by Foster et al. (8), this study leads us to the conclusion that athletes adjust their pace accordingly so that they reach their critically low values of $\mathrm{pH}$ near the end of the race, and the hypothesis of a lower critical $\mathrm{pH}$ value in worldclass runners compared with less experienced ones can be advanced.

\section{Practical Applications}

This study has shown that the best athletes are able to reach higher absolute and relative velocities (percent of their 200-m best performance). These higher velocities are obtained by a significantly greater stride length $(2.53$ and $2.29 \mathrm{~m}$ for the best men and women, respectively), resulting in significantly lower stride numbers $(172,179$, and 182 strides for MWC, $\mathrm{MN}$, and MR, respectively, and 185, 193, and 198 for WWC, $\mathrm{WN}$, and WR, respectively). Moreover, world-class athletes can be characterized by a greater loss of velocity in the second half of the race, mainly attributable to a greater decrease in stride length in the last $100 \mathrm{~m}$. These results demonstrate that the elite runner must be 1) a very fast runner for $200 \mathrm{~m}, 2$ ) able to adopt an important stride length, and 3) physiologically and psychologically able to adopt a more risky strategy than the less experienced ones. From a training point of view, this means that runners have to develop the velocity of ATP-PCr breakdown-the rate at which an athlete can supply ATP via anaerobic sources (12)-but also achieve a buffer capacity to compensate for $[\mathrm{H}+]$ production. Furthermore, the reduction in muscle $\mathrm{pH}$ as a result of the fast start implies that to prevent the loss of technique that may accompany the subsequent fatigue (7), technical training sessions should be planned under fatigue to force endurance in the implied muscles.

\section{ACKNOWLEDGMents}

The authors are grateful to the French Ministry of Health, Youth and Sport for their financial support and the French Athletics Federation for their technical assistance. 


\section{REFERENCES}

1. Bates, BT and Haven, BH. Effect of fatigue on the mechanical characteristics of highly skilled female runners. In: Biomechanics $I V$. Nelson, $\mathrm{C}$ and Morehouse, A, eds. Baltimore: University Park Press, 1974. pp. 121-125.

2. Belloc, O. 400 Haies: Les Enseignement du 400m Plat. Paris, France: Publications INSEP Collection Entraînement, 1990.

3. Bishop, D, Bonetti, D, and Dawson, B. The influence of pacing strategy on $\dot{\mathrm{V}}_{2}$ and supramaximal kayak performance. Med Sci Sport Exerc 34: 1041-1047, 2002.

4. Brüggeman, GP, and Glad, B. Time Analysis of the 400 Metres Hurdles Events. Scientific Research Project at the Games of the XXIVth OlympiadSeoul. Final Report. Oxford: International Athletic Foundation, 1988.

5. Brüggeman, GP, Koszewski, D, and Müller, H. Biomechanics Research Project Athens 1997. Scientific Bulletin 400m Sprint. Oxford: IAAF Foundation, 1999. pp. 54-62.

6. De Koning, JJ, Bobbert, MF, and Foster, C. Determination of optimal pacing strategy in track cycling with an energy flow model. J Sci Med Sport 2: 266-277, 1999.

7. Foster, CA, Snyder, AC, Thompson, NN, Green, MA, Foley, M, and Schrager, M. Effect of pacing strategy on cycle time trial performance. Med Sci Sports Exerc 25: 383-388, 1993.

8. Foster, CA, Schrager, M, Snyder, AC, and Thompson, NN. Pacing strategy and athletic performance. Sports Med 17: 77-85, 1994.

9. Gajer, B, and Thepaut-Mathieu, C. Evolution of stride and amplitude during course of the $100 \mathrm{~m}$ event in athletics. New Stud Athl 14: 43$50,1999$.

10. Gajer, B, Hanon, C, Marajo, J, and Vollmer, JC. Le 800 Mètres, Analyse Descriptive et Entrainement. Paris, France: Publications INSEP Collection Entraînement, 2000.

11. Hanon, C, Slawinski, J, Dorel, S, Hug, F, Couturier, A, Fournel, V, Garcia, J, and Senegas, X. Incline versus level maximal sprint running in elite athletes. In: Proceedings of the Science for Success II. Mononen, K,
Valleala, R, Blomqvist, M, and Viitasalo, J, eds. Jyvaskyla, Finland: KIHU, Research Institute for Olympic Sports, 2007. p. 57.

12. Hirvonen, J and Nummela, A. Fatigue and changes of ATP, créatine phosphate and lactate during 400m sprint. Can J Sport Sci 17: 141144, 1992.

13. LAF Scientific Report on the II World Championships in Athletics (2nd ed.). Rome: IAF, 1987.

14. Kinderman, W and Schnabel, A. Verhalten der anaeroben ausdaer bei 400m. Mittelstrecken und Langstrecklaüfern 31: 225-230, 1980.

15. Lacour, JR, Bouvat, E, and Barthelemy, JC. Post-competition blood lactate concentrations as indicators of anaerobic energy expenditure during 400-m and 800-m races. Eur J Appl Physiol 61: 172-176, 1990.

16. Mero, A Komi, PV, and Gregor, R. Biomechanics of sprint running. Sport Med 13: 376-392, 1992.

17. Mero, A and Luhtanen, P. Kinematics of top sprint $(400 \mathrm{~m})$ running in fatigued conditions. Track Field Q Rev1: 42-45, 1998.

18. Mero, A and Peltola, E. Neural activation fatigued and nofatigued conditions of short and long sprint running. Biol Sport 6: 43-53, 1989.

19. Morin, JB, Jeannin, T, and Chevalier, R. Spring-mass model characteristics during sprint running: correlation with performance and fatigue-induced changes. Int J Sports Med 27: 158-165, 2006.

20. Nummela, A, Vuorimaa, T, and Rusko, H. Changes in force production, blood lactate and EMG activity in the $400 \mathrm{~m}$ sprint. J Sport Sci 107: 217-228, 1992.

21. Scholich, M. Est German study of distance stride. Der Leichtathlet 78: 2355-2359, 1978.

22. Sprague, $\mathrm{P}$ and Mann, RV. The effects of muscular fatigue on the kinetics of sprint running. Res Q Exerc Sport 54: 60-66, 1983.

23. Tucker, R, Lambert, M, and Noakes, TD. An analysis of pacing strategies during men's world-record performances in track athletics. Int J Sports Physiol Perform 1: 223-245, 2006. 